\title{
Challenges of ICC and FISH in the Field of Targeted Therapies from Cell Block to Smears
}

\author{
Jose I. Echeveste ${ }^{1}$, Tania Labiano ${ }^{2}$, Eva Tejerina ${ }^{3}$, Allan Argueta ${ }^{1} \mathbb{D}$, Carlos de Andrea ${ }^{1}$ and Maria D. Lozano ${ }^{1, *}$ \\ 1 Department of Pathology, Clínica University of Navarra, 31008 Pamplona, Spain; jiecheves@unav.es (J.I.E.); \\ aargueta@unav.es (A.A.); ceandrea@unav.es (C.d.A.) \\ 2 Department of Pathology, Complejo Hospitalario de Navarra, 31008 Pamplona, Spain; labiano.t@gmail.com \\ 3 Department of Pathology, University Hospital Puerta de Hierro, 28222 Madrid, Spain; etejegon@telefonica.net \\ * Correspondence: mdlozano@unav.es; Tel.: +34-948-296-500
}

Citation: Echeveste, J.I.; Labiano, T.; Tejerina, E.; Argueta, A.; de Andrea, C.; Lozano, M.D. Challenges of ICC and FISH in the Field of Targeted Therapies from Cell Block to Smears. J. Mol. Pathol. 2021, 2, 55-65. https://doi.org/10.3390/jmp2020006

Academic Editor: Paul VanderLaan

Received: 26 February 2021

Accepted: 25 March 2021

Published: 30 March 2021

Publisher's Note: MDPI stays neutral with regard to jurisdictional claims in published maps and institutional affiliations.

Copyright: (c) 2021 by the authors. Licensee MDPI, Basel, Switzerland. This article is an open access article distributed under the terms and conditions of the Creative Commons Attribution (CC BY) license (https:/ / creativecommons.org/licenses/by/ $4.0 /)$.

\begin{abstract}
In the era of personalized medicine, there is an increasing demand for comprehensive and complex diagnosis using minimally invasive techniques. Nowadays, it is mandatory to integrate biomarkers in the diagnostic process, as well as in the treatment and clinical management of many cancer patients. Patients with non-small cell lung cancer (NSCLC), for instance, are frequently diagnosed in advanced stages, at a point when only cytological material or small biopsies can be obtained. This pathology constitutes an interesting challenge for the testing of biomarkers in cytology. Furthermore, there is a growing development of imaging techniques that guide non-invasive approaches to obtain small biopsies or cytological samples. This has allowed fine needle aspiration cytology and fine needle aspiration biopsy (FNAC, FNAB) to become front-line procedures in the management of patients with NSCLC. It is well known that the list of biomarkers to be tested in these patients continues to increase. Nevertheless, there are several of essential biomarkers that should always be analyzed in all patients with NSCLC, not only in non-squamous but also in some squamous carcinomas (SqCC). Some of them, such as PDL1, are tested by immunocytochemistry (ICC), while others, mainly ALK and ROS1, can be tested by ICC and confirmed using other techniques such a Fluorescence In Situ Hybridization (FISH). Other biomarkers, namely EGFR and BRAF mutations, are currently evaluated by polymerase chain reaction (PCR)-based techniques including Next-Generation Sequencing (NGS). In this review, we will address the particularities and challenges that ICC and FISH pose in different types of cytological samples from an eminently practical point of view.
\end{abstract}

Keywords: NSCLC; ICC; FISH; preanalytics; ROSE; cytological samples; small biopsies; smears

\section{Introduction}

Several publications to date support the fact that biomarkers can be tested in small biopsies and in any type of cytological samples, as long as the sample has adequate cellularity and preservation $[1,2]$. The use of cytological specimens for biomarker analysis in non-small-lung carcinoma (NSCLC) requires that every sample has adequate cellularity and proper preservation [3,4]. Nowadays, imaging techniques that enable non-invasive approaches have been developed, which allow proceduralists to obtain small biopsies or cytological specimens [5]. In this context, it is well known that Rapid On-Site Evaluation (ROSE) is a helpful procedure that enables the pathologist to secure an adequate sample management and control of pre-analytics, both of which are crucial to test biomarkers in these specimens [6,7].

Today, Fine-Needle Aspiration Cytology and Fine-Needle Aspiration Biopsy (FNA, FNAB) are mainstay procedures in the management of patients with NSCLC. It is well known that the list of biomarkers to be tested in patients diagnosed with this neoplasm is continuously increasing. Nevertheless, there are several biomarkers that continue to be essential and must always be analyzed in all patients with NSCLC, in non-squamous carcinomas, and in some squamous cell carcinomas (SqCC) $[3,4,8]$. Some of them, such as 
PDL1, are tested by immunocytochemistry (ICC) only with no need of confirmation, while others, mainly ALK and ROS1, may be tested by ICC and confirmed using other techniques such as Fluorescence In Situ Hybridization (FISH) [2]. Other biomarkers, namely EGFR and $B R A F$ mutations, are currently evaluated using polymerase chain reaction(PCR)-based techniques, such as Next-Generation Sequencing (NGS) [9].

Figure 1 shows the algorithm for sample collection morphological and biomarker diagnosis in NSCLC.

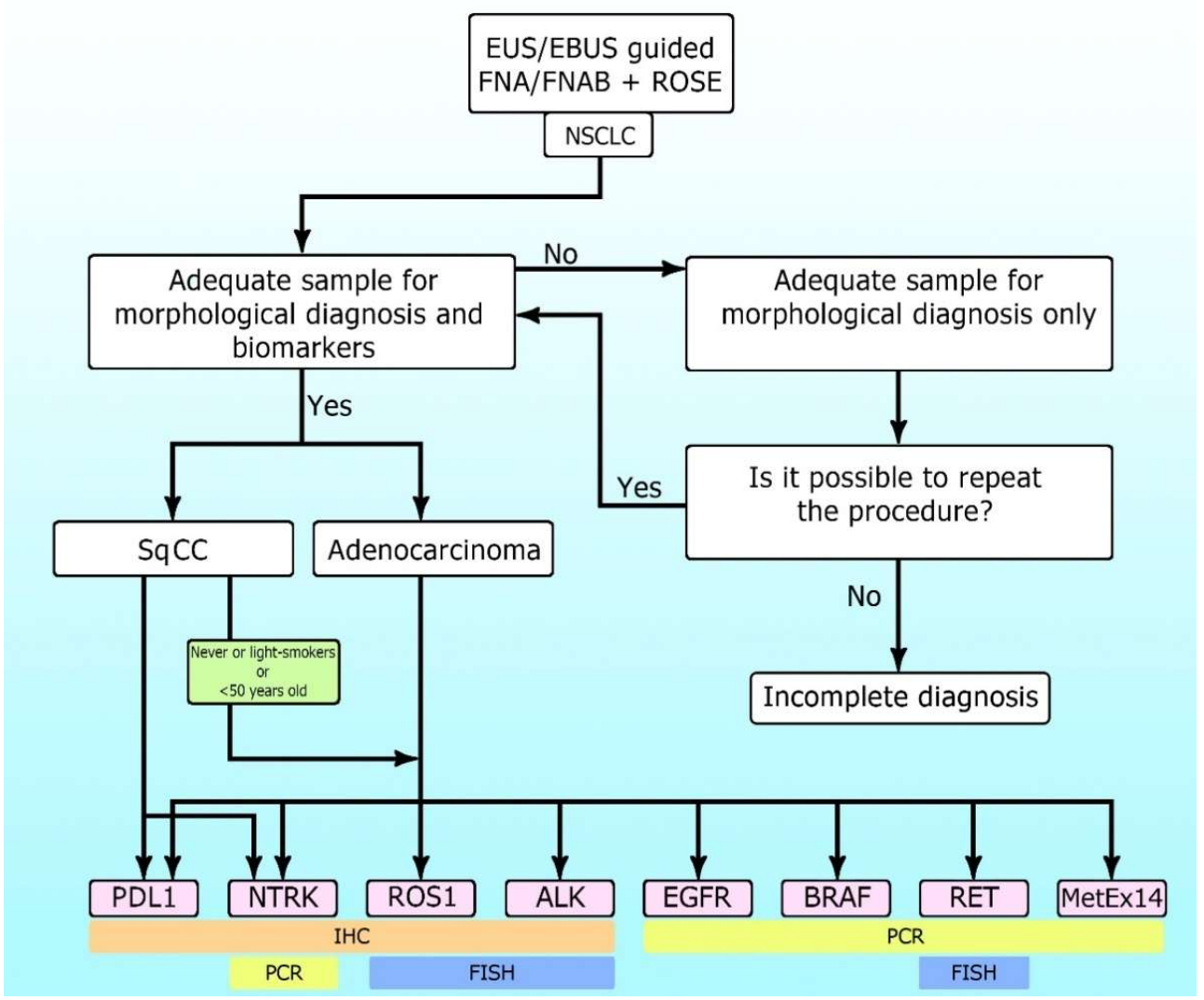

Figure 1. The algorithm for sample collection morphological and biomarker diagnosis in non-small cell lung cancer (NSCLC).

\section{Sample Management and ROSE}

The implementation of ICC and FISH in the study of cytological specimens poses many challenges and at the same time provide us with significant opportunities. The performance of any biomarker when employing cytological samples or small biopsies requires very careful handling of the specimens in terms of quality, quantity, and pre-analytical control. Each laboratory should optimize its protocols and procedures, develop adequate internal controls, and participate in external quality verification programs [10-12].

In most of EUS/EBUS procedures ROSE is recommended. ROSE decreases the number of false negatives results due to "inadequate sample", provides better diagnostic yields, allows for adequate triage of the samples for ancillary studies, and ensures an adequate processing of the samples by maximizing the control of the pre-analytical phase. On the other hand, costs, time investment by cytotechnologists and cytopathologists and required expertise are some of the cons of this procedure. In addition, it is important to consider the patient dissatisfaction and concerns associated with a need for a repeated procedure. Table 1 shows the main advantages and disadvantages of ROSE. 
Table 1. Main advantages and disadvantages of Rapid On-Site Evaluation (ROSE).

\begin{tabular}{|c|c|}
\hline PROS & CONS \\
\hline Less false negative results due to "inadequate sample" & Cost \\
\hline Higher diagnostic yield & Time/cytotechnician/cytopathologist \\
\hline Adequate triage for ancillary techniques & Experienced staff is needed \\
\hline Adequate processing of the sample & \\
\hline
\end{tabular}

One of the drawbacks of cytology is the lack of tissue architecture. The preservation of the neoplastic architecture in cytology samples is challenging to achieve and remains vital, especially when considering the future development of new promising diagnostic markers. Nowadays, the conventional procedures of FNA, FNAB, and cell blocks allow pathologists to obtain samples that preserve tissue architecture to some extent in a considerable number of cases. Furthermore, new FNA procedures and tools (needles, for example) that facilitate the extraction of thin tissue cylinders have been developed (Figure 2). Wet Suction FNA Technique (WEST), for instance, is a procedure where saline solution is added to the syringe in order to increase negative suction pressure. It has been shown that using this technique renders cell blocks with significantly superior cellular density than that provided by classical FNA, and that obtained from small biopsies ("direct" cell blocks) which are subsequently formalin-fixed and paraffin-embedded (FFPE). Although developed and validated in 2015 [13], WEST is not yet widely used (Figure 3). This approach has many advantages: it enables the simultaneous management of smears, other types of cytological samples, and cell blocks; it combines the advantages of different fixatives- alcohol and paraffin-; it allows pathologists to choose the most appropriate sample for each technique (ICC-tissue vs. FISH-cytological smear); it facilitates patient enrollment in clinical trials that do not accept classical cytological samples such as smears or liquid-based samples; it incorporates the possibility of implementing complex molecular studies and it enables the study of the immune microenvironment.

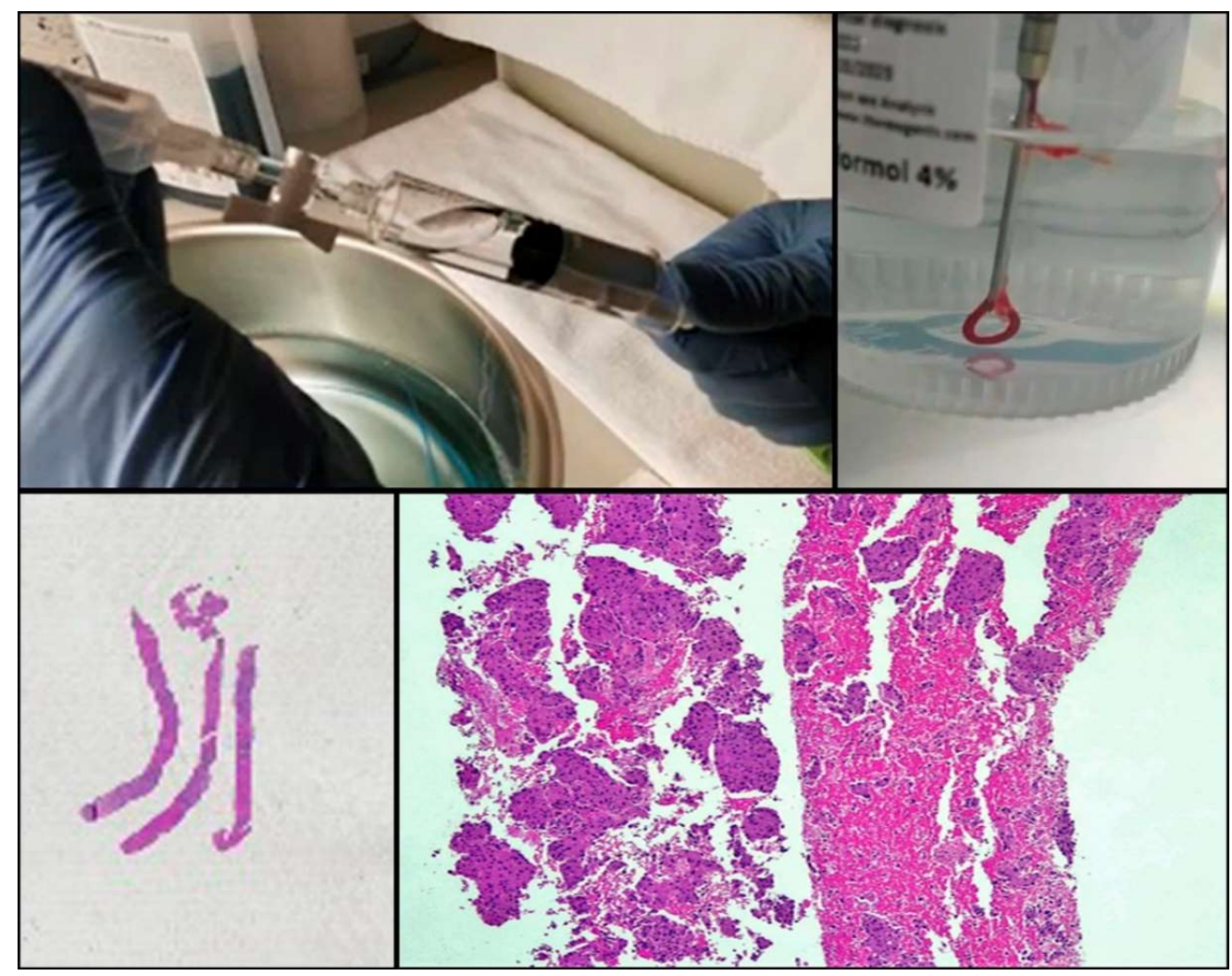

Figure 2. Procurement of cytological samples and small tissue that is directly introduced in formalin. 


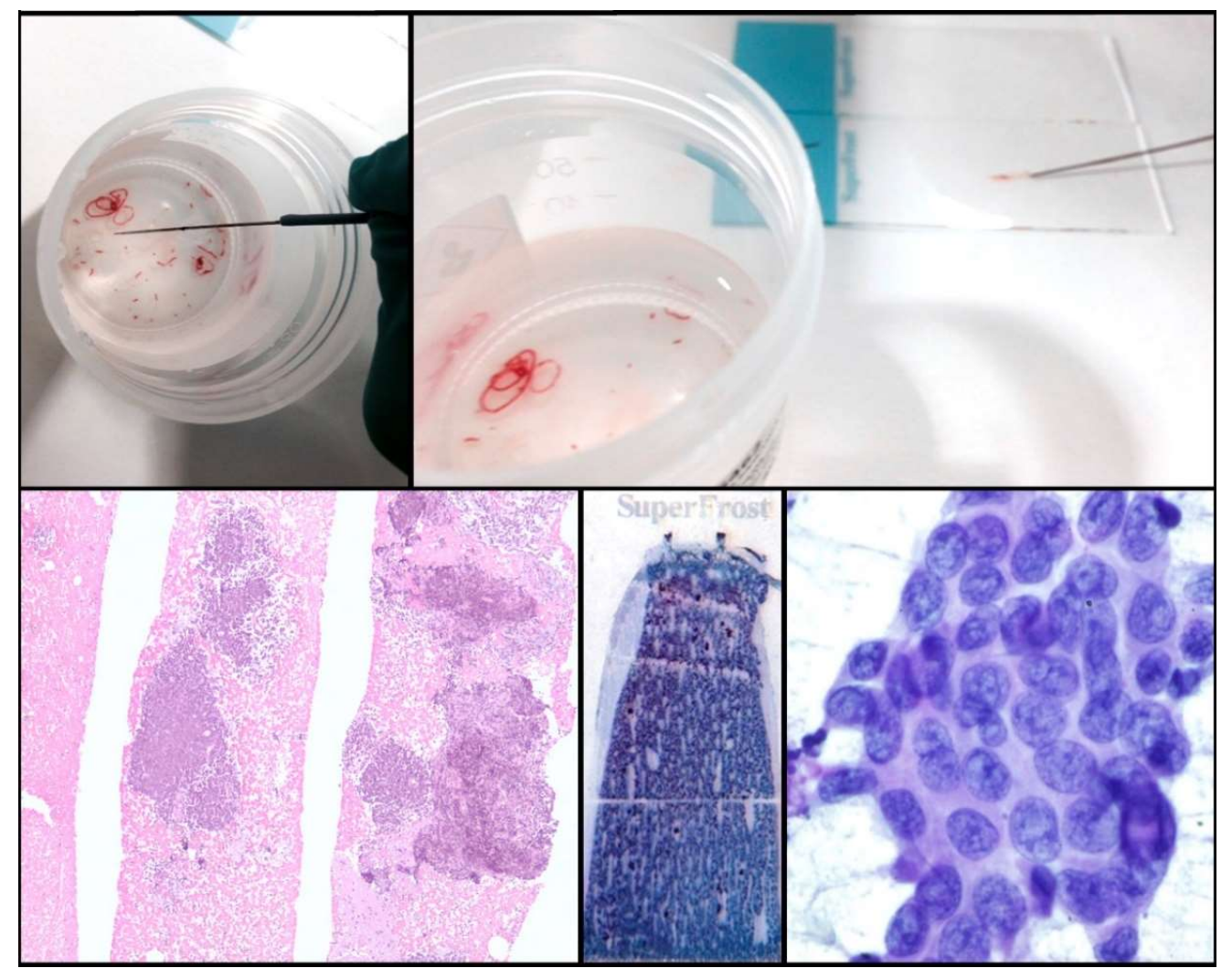

Figure 3. Wet Suction procedure.

\section{ICC in Cytological Samples}

Publications regarding best practice guidelines for ICC are relatively scarce $[3,14]$. Many laboratories perform diagnostic ICC without adequate validation or quality control standards. Nevertheless, there is evidence enough to assert that, with the appropriate modifications in analytical factors, ICC in non-cell block preparations can be equivalent to ICC in FFPE cell block sections. The main challenge to face is the need of the standardization of procedures which sometimes leads to a certain loss of enthusiasm in the event that some results do not meet expectations. A study of the United Kingdom National External Quality Assessment Scheme (UK NEQAS) for immunohistochemistry emphasizes that unifying criteria of the internal and external quality assurance could facilitate the further improvement and standardization of ICC in cytological samples. Not surprisingly, they observed better results in cell blocks (in which the conditions of the assays do not have to be modified) followed by cytospins, FFPE-sections, liquid-based cytology, and smears. Acetone-fixed slides achieved significantly lower scores than other fixatives. They conclude that good quality immunocytochemical staining can be achieve on cytology slides prepared and fixed in different ways as well as cell blocks, emphasizing the importance of adequate internal and external controls and standardization of procedures [11].

The International Association for the Study of Lung Cancer (IASLC) states that cytology samples (non-cell block preparations), which are often more versatile and easily available than other sample-types, remain frequently unused in daily clinical practice and are therefore underutilized for predictive ICC testing [15]. Using proper optimization and rigorous controls, high quality ICC staining can be achieved on non-cell block preparations. The new IASLC atlas of diagnostic immunohistochemistry states the following: "all cytology preparations including cell blocks, ethanol-fixed, and air-dried slides can principally be used for immunostaining. Formalin-fixed cell blocks are most straightforward and most commonly used. Rigorous protocol optimization, validation, and quality control are required in immunostaining cytology specimens, particularly in non-cell block preparations" [16]. In the pre-analytical phase, 
there are some factors that can influence the final result of ICC in cytological samples. For each of them it is necessary to take into account several considerations:

1. Fixatives: Acetone-fixed slides achieve a significantly lower score of immunostaining than other fixatives.

2. Preparations: A study of the UK NEQAS reported better global results when performing ICC in cell blocks, followed by cytospins, FFPE sections, liquid-based cytology, and smears. The conditions of the assays do not have to be modified when performed on cell blocks; not surprisingly, cell block is the most frequent type of cytological sample selected for ancillary techniques [11].

3. Stains: Any type of staining (Papanicolaou, Diff-Quik, Hematoxylin and Eosin (H\&E) can be used prior to immunocytochemistry. Pre-staining allows identification of tumor cells and selection of optimal fields in terms of state of preservation and number of neoplastic cells. Of the many different stains available, in our laboratory we prefer to use Papanicolaou-stained smears.

4. Coverslipping and mounting media: We use plastic coverslipping instead of the classic glass coverslip (Tissue-Tek film Sakura). Plastic coverslipping is faster and easier to remove and does not require the step of dipping the preparations in xylene solution in order to dissolve the nonaqueous permanent mounting media. Therefore it aids in avoiding cell loss [17].

5. Antigen retrieval: In contrast to formalin, which is a cross-linking fixative that masks most epitopes, alcohol-based fixatives work by causing tissue dehydration and protein coagulation. Thus, the majority of cytoplasmic and nuclear antigens do not need antigen retrieval [12,17].

Consequently, rigorous validation and protocol optimization should be performed in each laboratory depending on which type of specimen is used for ICC $[2,12,18]$. Table 2 shows the performance of the different types of cytological samples and fixatives.

Table 2. Performance of the different types of cytological samples and fixatives.

\begin{tabular}{ccc}
\hline Type of Cytological Samples & Fixative & Results \\
\hline CellBlock & Formalin & Comparable results to surgical samples \\
Papanicolaou-stained smears & Alcohol 96\% & Comparable results to surgical samples \\
Unstained smears & Alcohol 96\% & Slightly lower but OK \\
HQ & No fixh rate of false negative \\
Liquid based & & Low intensity of immunostaining \\
& Methanol-based fixatives & High rate of false negative \\
& & Low intensity of immunostaining
\end{tabular}

In the scenario of NSCLC patients, ALK and ROS1 can be evaluated by ICC. A case is considered positive for ALK and ROS1 when a strong granular cytoplasmic staining is observed [19] (Figure 4). In order to be confident with the ICC interpretation, a large number of intra-laboratory validation analyses comparing ICC and FIH have to be performed. In order to obtain reliable results, it is therefore essential that each laboratory develops its own internal quality controls.

Regarding PDL1 testing, it has been demonstrated that the quantification of PDL1 expression is feasible and reliable for the commercially available clones 22C3 and SP263 in direct stained cytological smears [17]. The staining criterion to classify a sample as positive is similar to that established for FFPE specimens, that is, partial or total cytoplasmic staining of any intensity [2,17,20-25] (Figure 5). However, due to the intrinsic morphological peculiarities of the cytological samples, some caution is advisable. The evaluation of three-dimensional groups due to the cellular overlapping can lead to a false interpretation of cytoplasmic staining. Similarly, unspecific staining can be observed in areas with abundant necrotic debris. Again, the use of quality controls in the procedure is essential [2]. The inclusion of positive and negative controls is mandatory. We recommend the use of 
placental tissue as a positive control, either in the form of smears when testing Papanicolaoustained slides or in FFPE sections when evaluating cell blocks [21] (Figure 6).

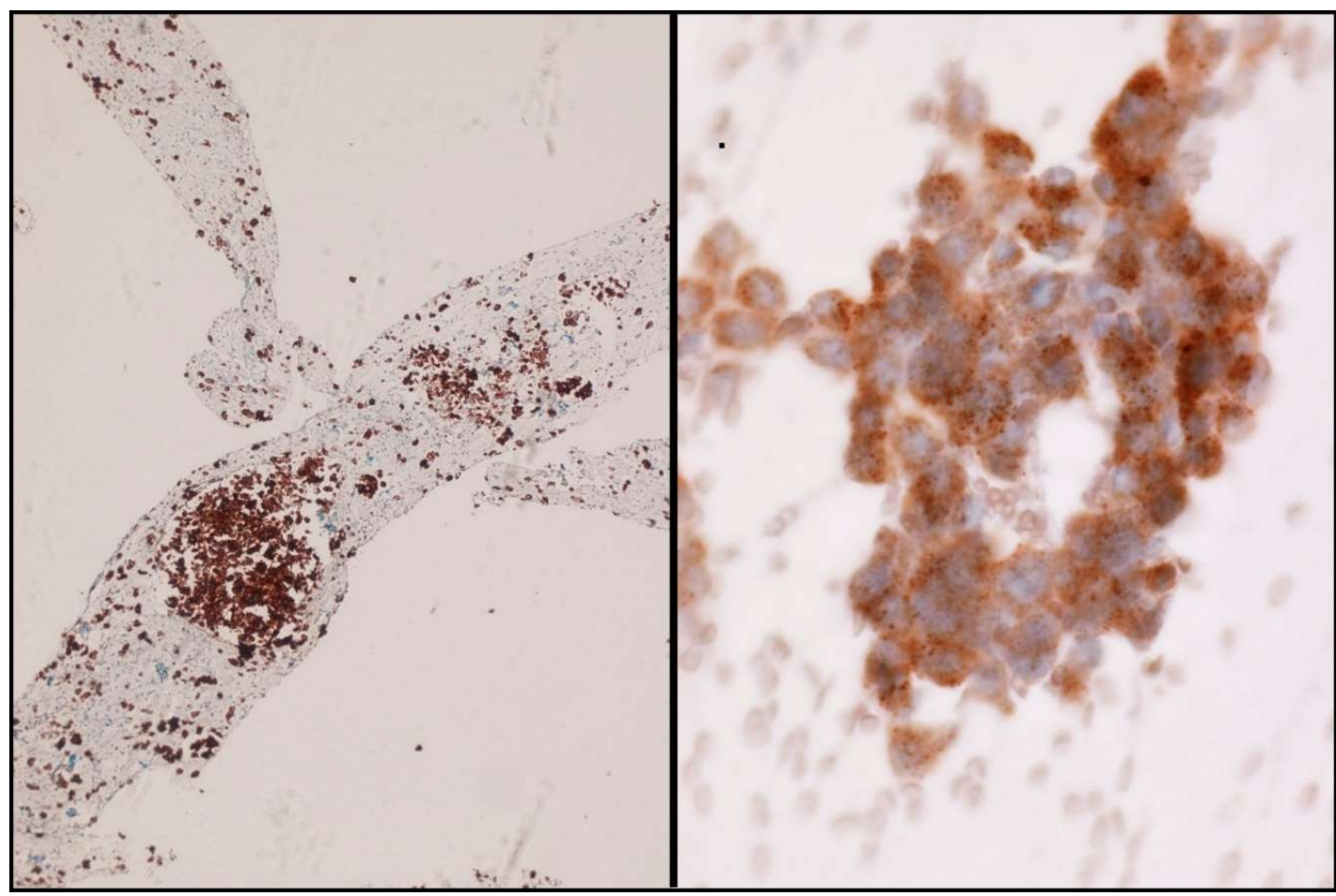

Figure 4. Some examples of ALK immunostaining. Cell-block (Left) and smear (Right).

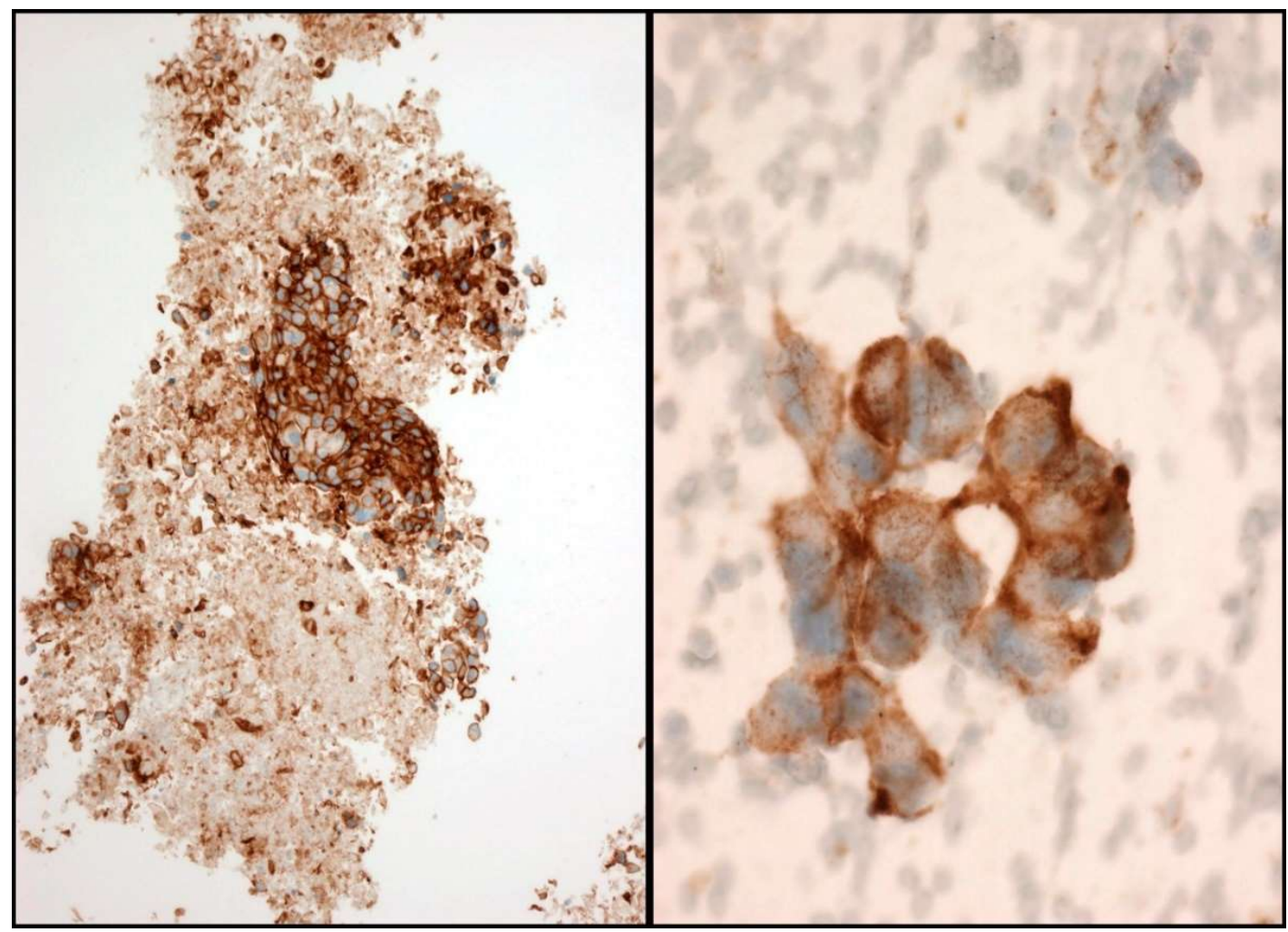

Figure 5. Some examples of PD-L1 immunostaining. Cell-block (Left) and smear (Right). 


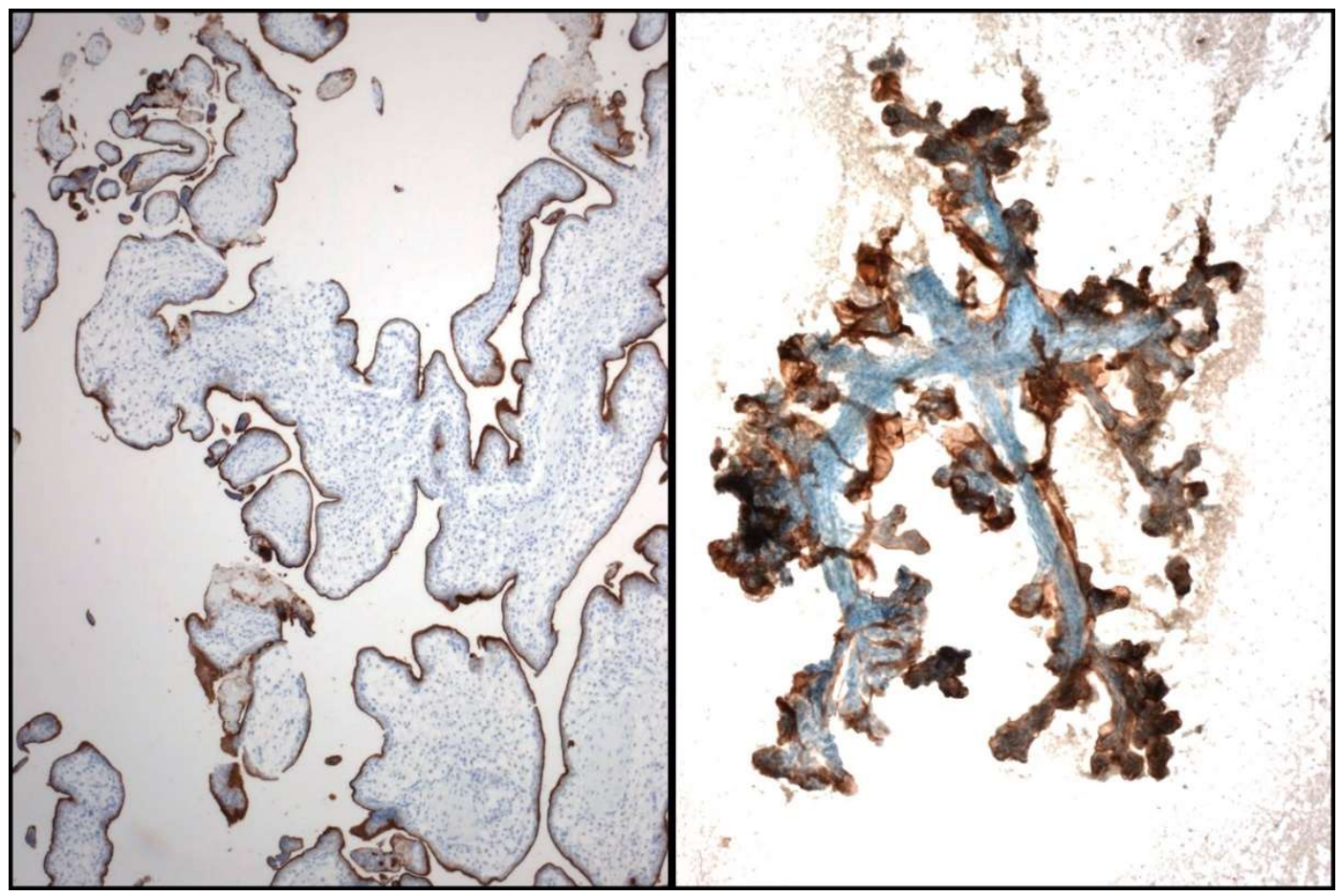

Figure 6. Controls used for PD-L1: formalin-fixed and paraffin-embedded (FFPE) Placenta tissue (Left) and smears (Right).

In the PDL1 ICC report, the percentage of viable tumor cells positive for this marker should be included, as well as the type of cytological sample, the clone of antibody selected, and the use of controls. At least 100 well-preserved, not overlapped cells should be analyzed, and pre-analytics should be strictly controlled [21].

\section{FISH in Cytological Samples}

The main advantage of performing FISH on cytology is that nuclei are not truncated in cytological smears, so the true number of signals per nucleus can be observed [26-29]. In fact, the last edition of the World Health Organization (WHO) classification of lung and mediastinal tumors suggests that cytological smears are likely preferable to histological sections for ALK FISH testing because they eliminate misinterpretation related to nuclear truncation [30] p. 24. Cell blocks are usually preferred by many laboratories for performing FISH because they can be handled analogously to surgical specimens; nevertheless, a significant number of them contain too few neoplastic cells for molecular testing. The quality of DNA in air-dried or alcohol-fixed cytological samples is better than after formaldehyde fixation. FISH works equally well in Giemsa/Papanicolau/H\&E smears and in unstained smears [2]. More than 50 cells with entire nuclei, isolated or in monolayered sheets, should be evaluated; similar to ICC, three-dimensional groups with overlapping nuclei and areas with necrosis should be avoided.

As previously mentioned, in our laboratory we perform FISH in order to confirm the results of ALK and ROS1 by ICC. Regarding ALK, it is not infrequent, especially in cases of doubtful immunostaining, to detect polysomy by FISH; such cases are therefore considered negative (Figure 7). 


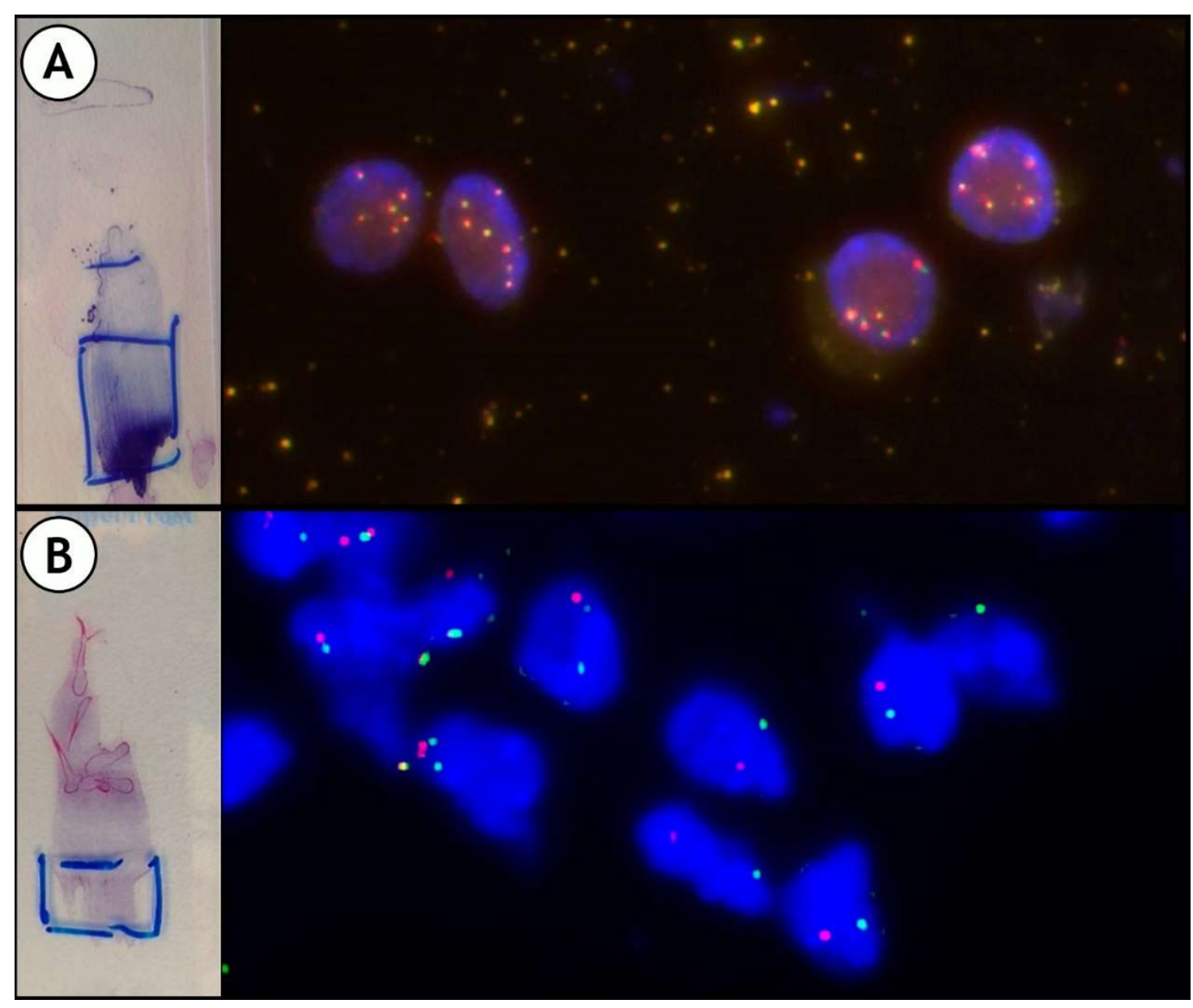

Figure 7. Some examples of Fluorescence In Situ Hybridization (FISH): (A): ALK polysomic; (B): and ROS1 rearranged. Split of green and red signals.

FISH performed on conventional smears has some advantages, among which are: (1) performing ROSE allows for an immediate evaluation and an optimal preservation of the sample for the analytical phase; (2) it avoids fixation-related alterations and probe tissue-related artefactual loss; and (3) the intrinsic characteristics of the cytological samples preserves the nuclear integrity. The main disadvantage of this procedure is cell overlapping and, mainly, legal issues regarding the use of diagnostic slides. Digital scanning of selected or appropriated fields prior to the procedure is therefore recommended. In our laboratory we use either Papanicolaou-stained or Diff-Quik smears evaluating at least 50 (Even better if you have one hundred!), well-preserved, not overlapped cells.

Although cell blocks preserve tissue architecture and avoid nuclear overlapping, they have certain limitations when evaluating FISH technique. If the cell block is appropriate in terms of cellularity, in practice it can be difficult to identify tumor cells in a dark field. In addition, the wide variety of cell block processing protocols can introduce an additional factor of variability in the results.

ICC and FISH are very useful, not only in NSCLC, (Figure 8), but also in other neoplasms such as small round cell sarcomas, other types of mesenchymal tumors, lymphomas, breast cancers, and several others [31]. 


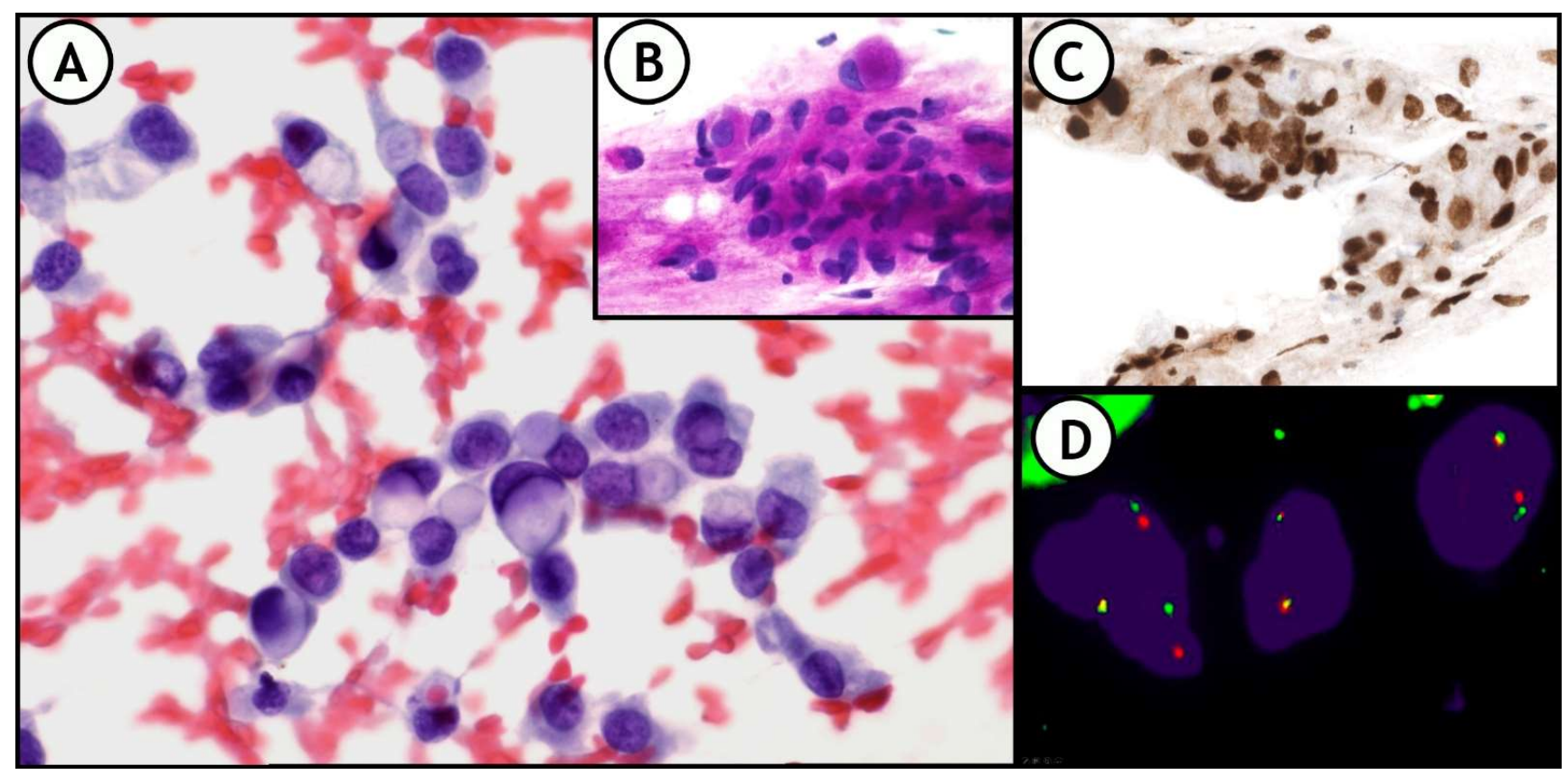

Figure 8. (A) representative example of the integration of these techniques in daily practice. 36-year-old woman. FNA of right supraclavicular lymph node shows metastasis of signet ring cell adenocarcinoma of lung origin. (A): Pap-stained smear; (B): PAS stain showing intracytoplasmic PAS positive vacuoles; (C): Nuclear positivity for TTF1. (D): FISH-ALK demonstrates the presence of the translocation.

\section{Summary and Conclusions}

In conclusion, ICC and FISH can be efficiently and reliably tested on any type of cytological sample, including stained smears. ROSE is highly recommended because it allows a careful management of the sample and a better control of the factors involved in the preanalytical phase, which is critical to the success of the procedure. Due to the higher DNA quality, the preservation of the integrity of nuclei and the guarantee of a more efficient hybridization, FISH achieves excellent results when performed on cytological smears, both Papanicolaou and Diff-Quik-stained. Digital scanning of the samples, previous to the procedure, especially of the most appropriate fields, is thoroughly recommended.

Author Contributions: J.I.E., T.L., E.T., A.A., C.d.A. and M.D.L.: Methodology, investigation, data curation, writing-review and editing. M.D.L.: Conceptualization, methodology, investigation, data curation, project administration, supervision, writing-original draft writing-review and editing. All authors have read and agreed to the published version of the manuscript.

Funding: This research received no external funding.

Institutional Review Board Statement: Not applicable.

Informed Consent Statement: Informed consent was obtained from all subjects involved in the study.

Data Availability Statement: Data sharing not applicable.

Acknowledgments: We thank Nerea Gomez, Nassira Fernandez, Mercedes Aguirre, and M Eugenia Echarri, for the expert technical help.

Conflicts of Interest: The authors declare no conflict of interest. 


\section{References}

1. Lozano, M.D.; Labiano, T.; Echeveste, J.; Gurpide, A.; Martín-Algarra, S.; Zhang, G.; Sharma, A.; Palma, J.F. Assessment of EGFR and KRAS mutation status from FNAs and core-needle biopsies of non-small cell lung cancer. Cancer Cytopathol. 2015, 123, 230-236. [CrossRef]

2. Lozano, M.D.; Echeveste, J.I.; Abengozar, M.; Mejías, L.D.; Idoate, M.A.; Calvo, A.; De Andrea, C.E. Cytology smears in the era of molecular biomarkers in non-small cell lung cancer doing more with less. Arch. Pathol. Lab. Med. 2018, 142, 291-298. [CrossRef] [PubMed]

3. Lindeman, N.I.; Cagle, P.T.; Aisner, D.L.; Arcila, M.E.; Beasley, M.B.; Bernicker, E.H.; Colasacco, C.; Dacic, S.; Hirsch, F.R.; Kerr, K.; et al. Updated molecular testing guideline for the selection of lung cancer patients for treatment with targeted tyrosine kinase inhibitors guideline from the college of American pathologists, the international association for the study of lung cancer, and the association for molecular pathology. Arch. Pathol. Lab. Med. 2018, 142, 321-346. [CrossRef] [PubMed]

4. Osmani, L.; Askin, F.; Gabrielson, E.; Li, Q.K. Current WHO guidelines and the critical role of immunohistochemical markers in the subclassification of non-small cell lung carcinoma (NSCLC): Moving from targeted therapy to immunotherapy. In Seminars in Cancer Biology; Academic Press: Cambridge, MA, USA, 2018; Volume 52, pp. 103-109. Available online: https: / / pubmed.ncbi.nlm.nih.gov/29183778/ (accessed on 25 February 2021).

5. Reck, M.; Rabe, K.F. Precision Diagnosis and Treatment for Advanced Non-Small-Cell Lung Cancer. N. Engl. J. Med. 2017, 377, 849-861. [CrossRef]

6. Jain, D.; Allen, T.C.; Aisner, D.L.; Beasley, M.B.; Cagle, P.T.; Capelozzi, V.L.; Hariri, L.P.; Lantuejoul, S.; Miller, R.; Mino-Kenudson, M.; et al. Rapid on-site evaluation of endobronchial ultrasound-guided transbronchial needle aspirations for the diagnosis of lung cancer a perspective from members of the Pulmonary Pathology Society. Arch. Pathol. Lab. Med. 2018, 142, 253-262. [CrossRef] [PubMed]

7. Gilbert, C.R.; Wahidi, M.M.; Yarmus, L.B.; Roy-Chowdhuri, S.; Pastis, N.J. Key Highlights for the College of American Pathology Statement on Collection and Handling of Thoracic Small Biopsy and Cytology Specimens for Ancillary Studies. Chest 2020, 158, 2282-2284. [CrossRef] [PubMed]

8. Garrido, P.; Conde, E.; De Castro, J.; Gómez-Román, J.J.; Felip, E.; Pijuan, L.; Isla, D.; Sanz, J.; Paz-Ares, L.; López-Ríos, F. Updated guidelines for predictive biomarker testing in advanced non-small-cell lung cancer: A National Consensus of the Spanish Society of Pathology and the Spanish Society of Medical Oncology. Clin. Transl. Oncol. 2020, 22, 989-1003. [CrossRef] [PubMed]

9. Roy-Chowdhuri, S.; Roy, S.; Pantanowitz, L. Next-Generation Sequencing in Cytopathology. In Monographs in Clinical Cytology; S. Karger AG: Berlin, Germany, 2020; pp. 34-42.

10. Sauter, J.L.; Grogg, K.L.; Vrana, J.A.; Law, M.E.; Halvorson, J.L.; Henry, M.R. Young investigator challenge: Validation and optimization of immunohistochemistry protocols for use on cellient cell block specimens. Cancer Cytopathol. 2016, 124, 89-99. [CrossRef] [PubMed]

11. Kirbis, I.S.; Maxwell, P.; Fležar, M.S.; Miller, K.; Ibrahim, M. External quality control for immunocytochemistry on cytology samples: A review of UK NEQAS ICC (cytology module) results. Cytopathology 2011, 22, 230-237. [CrossRef] [PubMed]

12. Jain, D.; Nambirajan, A.; Borczuk, A.; Chen, G.; Minami, Y.; Moreira, A.L.; Motoi, N.; Papotti, M.; Rekhtman, N.; Russell, P.A.; et al. Immunocytochemistry for predictive biomarker testing in lung cancer cytology. Cancer Cytopathol. 2019, 127, 325-339. [CrossRef]

13. Attam, R.; Arain, M.A.; Bloechl, S.J.; Trikudanathan, G.; Munigala, S.; Bakman, Y.; Singh, M.; Wallace, T.; Henderson, J.B.; Catalano, M.F.; et al. "wet suction technique (WEST)": A novel way to enhance the quality of EUS-FNA aspirate. Results of a prospective, single-blind, randomized, controlled trial using a 22-gauge needle for EUS-FNA of solid lesions. Gastrointest. Endosc. 2015, 81, 1401-1407. [CrossRef]

14. Layfield, L.J.; Esebua, M.; Dodd, L.; Giorgadze, T.; Schmidt, R.L. The Papanicolaou Society of Cytopathology guidelines for respiratory cytology: Reproducibility of categories among observers. CytoJournal 2018, 15, 22. [CrossRef] [PubMed]

15. Yatabe, Y.; Dacic, S.; Borczuk, A.C.; Warth, A.; Russell, P.A.; Lantuejoul, S.; Beasley, M.B.; Thunnissen, E.; Pelosi, G.; Rekhtman, N.; et al. Best Practices Recommendations for Diagnostic Immunohistochemistry in Lung Cancer. J. Thorac. Oncol. 2019, 14, 377-407. [CrossRef] [PubMed]

16. The IASLC Atlas of Diagnostic Immunohistochemistry (IHC) I IASLC. Available online: https://www.iaslc.org/researcheducation/publications-resources-guidelines/iaslc-atlas-diagnostic-immunohistochemistry (accessed on 25 February 2021).

17. Lozano, M.D.; Abengozar-Muela, M.; Echeveste, J.I.; Subtil, J.C.; Bertó, J.; Gúrpide, A.; Calvo, A.; De Andrea, C.E. Programmed death-ligand 1 expression on direct Pap-stained cytology smears from non-small cell lung cancer: Comparison with cell blocks and surgical resection specimens. Cancer Cytopathol. 2019, 127, 470-480. [CrossRef] [PubMed]

18. Roy-Chowdhuri, S.; Dacic, S.; Ghofrani, M.; Illei, P.B.; Layfield, L.J.; Lee, C.; Michael, C.W.; Miller, R.A.; Mitchell, J.W.; Nikolic, B.; et al. Collection and Handling of Thoracic Small Biopsy and Cytology Specimens for Ancillary Studies: Guideline From the College of American Pathologists in Collaboration With the American College of Chest Physicians, Association for Molecular Pathology, American Society of Cytopathology, American Thoracic Society, Pulmonary Pathology Society, Papanicolaou Society of Cytopathology, Society of Interventional Radiology, and Society of Thoracic Radiology. Arch. Pathol. Lab. Med. 2020, 144, 933-958. [CrossRef]

19. The IASLC Atlas of ALK and ROS1 Testing in Lung Cancer I IASLC. Available online: https:/ / www.iaslc.org/research-education/ publications-resources-guidelines/iaslc-atlas-alk-and-ros1-testing-lung-cancer (accessed on 25 February 2021). 
20. Kuempers, C.; van der Linde, L.I.S.; Reischl, M.; Vogel, W.; Stellmacher, F.; Reck, M.; Heigener, D.; Rabe, K.F.; Kirfel, J.; Perner, S.; et al. Comparison of PD-L1 expression between paired cytologic and histologic specimens from non-small cell lung cancer patients. Virchows Arch. 2020, 476, 261-271. [CrossRef]

21. The IASLC Atlas of PD-L1 Testing in Lung Cancer IIASLC. Available online: https://www.iaslc.org/research-education/ publications-resources-guidelines/iaslc-atlas-pd-11-testing-lung-cancer (accessed on 25 February 2021).

22. Mino-Kenudson, M. Programmed death-ligand 1 immunohistochemistry testing for non-small cell lung cancer in practice. In Cancer Cytopathology; John Wiley and Sons Inc.: Hoboken, NJ, USA, 2017; Volume 125, pp. 521-528. [CrossRef]

23. Vigliar, E.; Malapelle, U.; Bono, F.; Fusco, N.; Cortinovis, D.; Valtorta, E.; Spyridon, A.; Bimbatti, M.; Zocchi, M.; Piva, C.; et al. The Reproducibility of the Immunohistochemical PD-L1 Testing in Non-Small-Cell Lung Cancer: A Multicentric Italian Experience. BioMed Res. Int. 2019, 2019, 6832909. [CrossRef]

24. Arriola, A.G.P.; Bashover, E.; Joseph, C.; Staerkel, G.; Wang, W.-L.; Roy-Chowdhuri, S. The usefulness of various cytologic specimen preparations for PD-L1 immunostaining in non-small cell lung carcinoma. J. Am. Soc. Cytopathol. 2018, 7, $324-332$. [CrossRef]

25. Bubendorf, L.; Conde, E.; Cappuzzo, F.; Langfort, R.; Schildhaus, H.; Votruba, J.; Concha-López, Á.; Esteban-Rodriguez, I.; Feng, J.; Devenport, J.; et al. A Noninterventional, Multinational Study to Assess PD-L1 Expression in Cytological and Histological Lung Cancer Specimens. Cancer Cytopathol. 2020, 128, 928-938. [CrossRef]

26. Savic, S.; Bode, B.; Diebold, J.; Tosoni, I.; Barascud, A.; Baschiera, B.; Grilli, B.; Herzog, M.; Obermann, E.; Bubendorf, L. Detection of ALK-positive non-small-cell lung cancers on cytological specimens: High accuracy of immunocytochemistry with the 5A4 clone. J. Thorac. Oncol. 2013, 8, 1004-1011. [CrossRef] [PubMed]

27. Knoepp, S.M.; Roh, M.H. Ancillary techniques on direct-smear aspirate slides a significant evolution for cytopathology techniques. Cancer Cytopathol. 2013, 121, 120-128. [CrossRef]

28. Betz, B.L.; Dixon, C.A.; Weigelin, H.C.; Knoepp, S.M.; Roh, M.H. The use of stained cytologic direct smears for ALK gene rearrangement analysis of lung adenocarcinoma. Cancer Cytopathol. 2013, 121, 489-499. [CrossRef] [PubMed]

29. McLeer-Florin, A.; Moro-Sibilot, D.; Melis, A.; Salameire, D.; Lefebvre, C.; Ceccaldi, F.; De Fraipont, F.; Brambilla, E.; Lantuejoul, S. Dual IHC and FISH testing for ALK gene rearrangement in lung adenocarcinomas in a routine practice: A French study. J. Thorac. Oncol. 2012, 7, 348-354. [CrossRef] [PubMed]

30. Powerll, C.A.; Brambilla, E.; Bubendorf, L.; Dacic, S.; Dziadziuszko, R.; Geisinger, K.; Hirsch, F.R.; Ladanyi, M.; Meyerson, M.; Nicholson, A.G.; et al. Molecular testing for treatment selection in lung cancer. In WHO Classification of Tumours of the Lung, Pleura, Thymus and Heart; World Health Organization: Genève, Switzerland, 2015; Volume 7, p. 24.

31. Lozano, M.D.; Landa, A.; Tobar, L.G.; De Andrea, C.; Larrache, J.; Echeveste, J.I.; Paricio, J.J.; Sánchez, B.; Medina, A.; Paisan, A. A comprehensive diagnosis of a desmoplastic small round cell tumor of unusual location based on fine-needle aspiration cytology: Report of a case arising in the parotid gland and review of the literature. Diagn. Cytopathol. 2020, 48, 827-832. [CrossRef] [PubMed] 